\title{
Key opinion leaders' views regarding emergency contraception in India
}

\author{
M.E. Khan \\ Population Council \\ Isha Bhatnagar \\ Population Council \\ Deepthi S. Varma \\ Population Council \\ Anvita Dixit \\ Population Council
}

Follow this and additional works at: https://knowledgecommons.popcouncil.org/departments_sbsr-rh

Part of the Health Policy Commons, International Public Health Commons, Obstetrics and Gynecology Commons, Pharmacy and Pharmaceutical Sciences Commons, Public Health Education and Promotion Commons, and the Women's Health Commons

How does access to this work benefit you? Let us know!

\section{Recommended Citation}

Khan, M.E., Isha Bhatnagar, Deepthi S. Varma, and Anvita Dixit. 2012. "Key opinion leaders' views regarding emergency contraception in India," program brief. New York: Population Council. 


\title{
KEY OPINION LEADERS' VIEWS REGARDING EMERGENCY CONTRACEPTION IN INDIA
}

FEBRUARY 2012

\author{
By M.E. Khan, Isha Bhatnagar, Deepthi S. Varma, Anvita Dixit
}

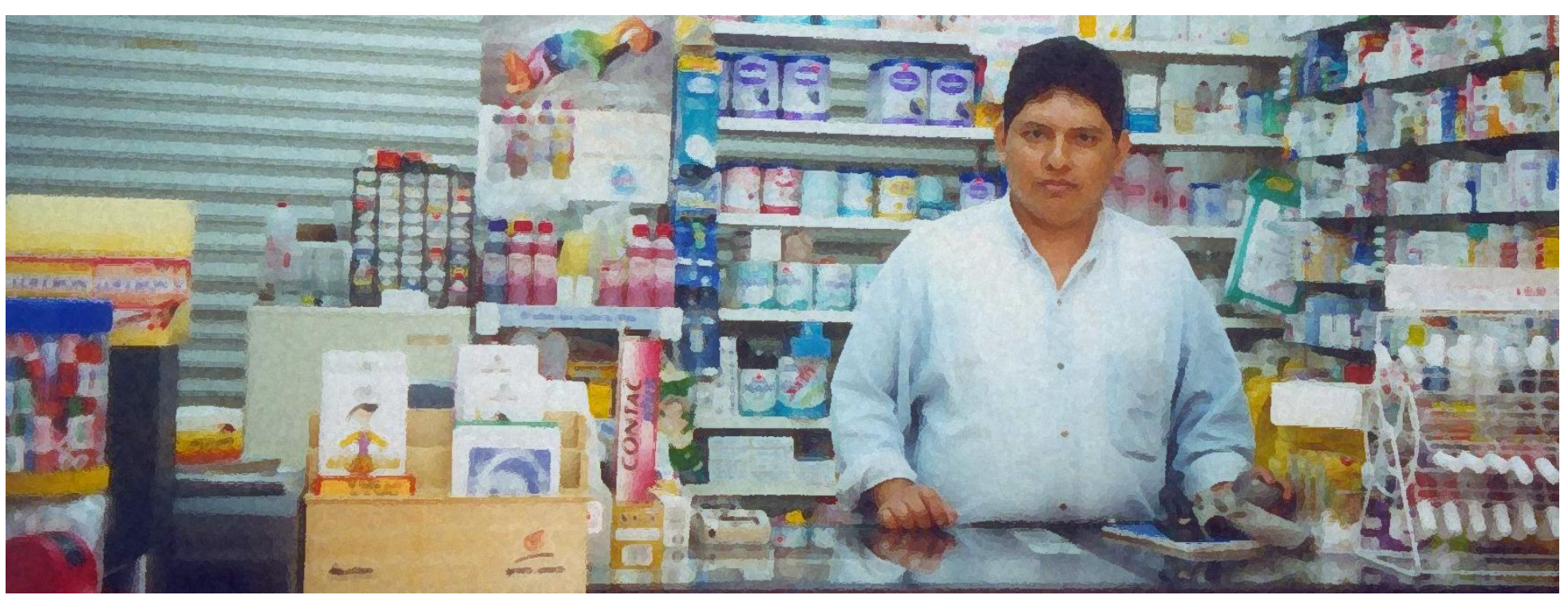

\section{BACKGROUND}

The emergency contraception pill (ECP) was approved and introduced in the National Family Planning Program in 2002 and made available over the counter (OTC) in 2005. The first phase of this study on ECP providers in urban areas revealed that providers lack correct knowledge and often are not in favor of the easy availability of ECP to young and unmarried women. Concern about repeated use of ECP was also identified as an issue.

\section{OBJECTIVE}

This study explores the views of key opinion leaders (KOLs) in the field of reproductive health and family welfare. The objective is to gain a better understanding of how the attitudes and beliefs of KOLs might influence policy and program implementation, either encouraging or opposing ECP promotion and service delivery.

\section{METHODOLOGY}

A qualitative approach was used to interview 19 experts from Agra, Delhi, and Lucknow. Eight of these key opinion leaders were OB/GYNS from medical institutions, seven were government employees (senior program managers of the Ministry of Health and Family Welfare of Uttar Pradesh state and the central government), three were from development organizations, and one was from an ECP manufacturing firm.
An interview guideline was followed and interviews were recorded. Detailed notes were taken when informants were reluctant to have their opinions tape recorded.

Topics discussed included perceptions of the safety and effectiveness of ECP, attitudes toward appropriate contexts for use, reservations among providers, the association between access to ECP and promiscuity and premarital sex, and repeated use as a substitute for modern contraceptive methods. Recommendations to increase access and suggestions for further research were also discussed.

\section{FINDINGS}

- All eight OB/GYNS reported that ECP is a safe and effective product that works by delaying or inhibiting ovulation. Government and program officials were not as certain regarding the mechanism of action of ECP.

- Eight KOLs expressed that ECP use is appropriate in the case of contraceptive failure, and two felt that it is appropriate for women who have infrequent sexual relations. Thirteen KOLs considered use appropriate only in emergencies. 
- Seven respondents felt that use should be permitted for any woman regardless of her age or marital status. The other respondents were in support of one or another restriction.

- Three respondents related premarital sex and promiscuity to ECP availability, ten deemed this association to be a misconception, and six were uncertain (and did not express a firm opinion).

- Eleven KOLs believed that increased availability of ECP will not lead to its becoming a substitute for regular contraceptive methods, and some believed it would foster use of other methods. As one respondent noted, "In my experience, if ten women have taken ECP, then eight would go for a regular method, so users do move to regular methods."

Eight KOLs were concerned that it may push clients away from regular contraception.

- KOLs' perceptions of challenges to ECP provision among providers include lack of knowledge and lack of training (11), little counseling time (5), insufficient access to ECP in rural areas (9), and low program focus (4).

- All KOLs were concerned about repeated use, but their definitions of repeated use and their perceptions of the frequency of its occurrence varied.

- $\quad$ Five out of 19 expressed concern about OTC availability and were worried about negative consequences of repeat use, such as menstrual disturbance or ECP failure. "When they come to us with abdominal pain or irregular bleeding, we find out that they were taking ECP many times in a cycle and mistaking irregular bleeding as menstrual bleeding, not realizing what repeat use was doing to their body." But six out of nine OB/GYNS expressed that ECP may lead to a decline in abortions.

- Thirteen KOLs stated that media messages need to emphasize that ECP is for emergency use only.
They also noted that adoption of modern contraceptive methods should be encouraged following ECP use, and that the side effects of repeated use need to be highlighted.

- KOLs suggested that further research be conducted on the failure rate of ECP due to repeat use, and the extent to which ECP use reduces abortion. One OB/GYN asked for a study to rule out whether ECP leads to ectopic pregnancy. Other suggestions included studying the extent to which ECP use is replacing use of other methods, the profile of repeat users, and the impact of repeated use on abortions.

\section{POLICY IMPLICATIONS}

These results suggest strong support by the majority of KOLs to continue the sale of ECP as an OTC drug. KOLs also emphasized the importance of comprehending and addressing the main barriers to ECP provision and use: poor knowledge, lack of training, moral reservations, biases, and misuse.

The majority of KOLs felt that use of ECP two or three times in one menstrual cycle was acceptable. They highlighted the need for empirical evidence to support their impression that use of regular family planning methods has not declined as a result of ECP use, and that use of ECP does not lead to increased promiscuity.

The KOL interviews also suggest the need for a strong ECP advocacy campaign, targeting providers as well as prospective users. Creating guidelines and clarifying ambiguities would reduce concerns among providers regarding repeated use of ECP replacing regular contraception and that an increased ECP use will increase promiscuity. And given that the majority of ECP users are educated urban young women who are upper-middle class or wealthy, such a campaign should target use among poorer women in rural areas.

\footnotetext{
The Population Council confronts critical health and development issues-from stopping the spread of HIV to improving reproductive health and ensuring that young people lead full and productive lives. Through biomedical, social science and public health research in about 50 countries, the Council works with our partners to deliver solutions that lead to more effective policies, programs, and technologies to improve lives worldwide. Established in 1952 and headquartered in New York, the Council is a nongovernmental, nonprofit organization with an international board of trustees.
} 